\title{
The Spleen and Sickle Cell Anemia: A Contrast Enhanced Computerized Tomography Based Study
}

\author{
Malaz Mohammed Ali Omer Ahmed, Caroline Edward Ayad \\ Sudan University of Science and Technology, College of Medical Radiological Science, Khartoum, Sudan \\ Email: carolineayad@yahoo.com
}

Received 18 June 2016; accepted 28 July 2016; published 2 August 2016

Copyright (C) 2016 by authors and Scientific Research Publishing Inc.

This work is licensed under the Creative Commons Attribution International License (CC BY). http://creativecommons.org/licenses/by/4.0/

(c) $\underset{\mathrm{EY}}{\mathrm{B}}$ 0pen Access

\section{Abstract}

The spleen is one of the most frequently affected organs in sickle cell anemia (SCA). This study aims to characterize the spleen in sickle cell anemia patients using contrast enhanced computerized tomography scanning (CECT). 67 patients with SCA from different Saudi Arabian areas were enrolled; ages are ranged from 10 months to 28 years old. The spleen was assessed with CT for abdominal pain and/or unexplained fever. The evaluation was done at different contrast enhancement scanning phases. The study showed that the least number of affected patients was from Eastern Saudi Arabia (1.5\%) followed by Asseer (16.4\%) then Gazan representing 82.1\%. The most common type of SCA affected the Saudi children is Hemoglobin SS Disease (Hb SS) constituting 41 (61.2\%). The spleen size, lymph nodes size, spleen Hounsfield (HU), splenic vein diameter and the correlation with the associated findings were evaluated for all of the patients. In children affected with SCA: $26(38.8 \%)$ have splenomegaly, $18(26.9 \%)$ have atrophied spleen and $2(3.0 \%)$ are with very small tissue like structure. Lesions found in the spleen were abscess, infarction, cyst, and calcifications. At the spleen hilum region; dilated splenic vein, presence of multiple collaterals, and thrombus were also been detected. Significantly correlations were noticed between lesions type, child age, enlargement of spleen and splenic lymph nodes at $P \leq 0.033, P \leq$ 0.010 and $P \leq 0.012$ respectively and showed an evidence that the reduction of the HU and advanced age have significant relation with changing of the spleen size at $P \leq 0.004$ and $P \leq 0.000$ respectively. Spleen lesions' enhancement pattern is well emerged in both venous and delay phase and it was significantly related with the scanning phase at $P \leq 0.000$ and with different types of SCA at $P \leq 0.037$, and $P \leq 0.055$ in venous and delay phase in respectively. CECT offers a number of morphological criteria that can be applied to differentiate hypodense lesions of the spleen in SCA. CT characterization criteria of hypodense splenic lesions are acknowledged to aid interpretation during evaluation of abdominal CT images of the spleen in symptomatic patients with sickle cell anemia. 


\section{Keywords}

\section{Spleen, Sickle Cell Disease, Computerized Tomography}

\section{Introduction}

Sickle cell disease (SCD) is a common genetic condition that causes ischemic vascular occlusion [1]. SCD affected different organs of the abdominal structures; the most commonly involved organ is the spleen, which is affected in almost all patients with Sickle Cell Anemia (SCA). The natural history is splenomegaly during the first decade of life and then autosplenectomy as a result of vaso-occlusion and infarction. Sometimes splenomegaly persists into an older age group or even adulthood [2]-[4]. Children with SCD are repeatedly exposed to diagnostic radiation. Plain radiographs are frequently ordered for pain, and chest radiographs are often ordered for fever and respiratory symptoms [5]. Computed tomography (CT) and nuclear medicine scans are ordered for other suspected complications [5], [6]. Direct visualization of suspected splenic disease with various imaging modalities has always been a challenge [7]. Ultrasonography (US) is frequently the first imaging modality used to evaluate the spleen. Color Doppler is useful in the evaluation of vascular pathology in the splenic hilum. Splenic focal lesions are frequently subtle and often nonspecific, appearing as hypoechoic lesions [8]. Therefore, focal heterogeneity detected on US should be further evaluated by computerized tomography (CT) or magnetic resonance imaging (MRI) [9]. Splenic lesions tend to be small or infiltrating, and without use of an organ-specific contrast agent, they tend to be difficult to detect [7]. The widespread use of CT represents probably the single most important advance in diagnostic radiology. However, CT involves much higher doses of radiation. Despite the fact that most diagnostic CT scans are associated with very favorable ratios of benefit to risk, many CT studies are being performed in the United States [10] [11], questioning the use of CT scans, in a variety of contexts, including blunt trauma [12] [13], seizures [14], and chronic headaches [15], and particularly its use as a primary diagnostic tool for children [16]. Expressively, pediatric radiologists suggested that perhaps one third of CT studies could be replaced by alternative approaches or not performed at all due to cancer risks associated with CT Scans [10]. On the other hand, on the unenhanced CT, the normal spleen is homogeneous with attenuation values ranging between 40 and 60 Hounsfield units (HU) [17]. On non-enhanced CT, infarcts are poorly visualized. After intravenous iodine contrast administration, the typical imaging findings are peripheral, wedgeshaped non-enhancing defects. However, this typical appearance is only present in less than half of all acute splenic infarcts [9]. In less typical cases, infarcts may mimic other splenic lesions, including abscesses or tumors, requiring clinical correlation, or if necessary, percutaneous fine-needle aspiration biopsy [17]. The enhancement pattern is caused by variable flow rates; this inhomogeneous enhancement pattern should not be confused with splenic disease. After intravenous contrast injection, the normal spleen enhances in a mottled pattern during the arterial and early portal venous phases giving the examination great value [18]. Splenic injury is generally silent and progressive. It can be clinically overt with acute splenic sequestration of red cells and an unpredictable complication in infants [19]. Knowledge about the CT imaging findings' characteristics of spleen in children with sickle cell anemia is important to avoid diagnostic pitfalls and misinterpretations of the early heterogeneity for focal hypointense splenic lesions; this was organized for early and proper diagnosis without need of unnecessary biopsy or unnecessary radiation exposure. In this study, we characterize the spleen abnormalities associated with SCD in all CT protocols of contrast media injection (arterial, venous phase) in order to explain the criteria in proper diagnosis for SCD done for children with SCA.

\section{Materials and Methods}

\subsection{Place and Duration of the Study}

This study was done in Ballasmar General Hospital and Fahad King Hospital CT departments, in Aseer and Gizan states (South of Saudi Arabia). Data were collected in the period spanned from June 2014 up to June 2015. The present study was approved by the Ethics Committee of the Research council, College of Medical Radiological Science as well as the Approval of the Radiology Departments. Verbal consent was obtained from all potential participants. The aims, benefits of the present study were explained to all participants in details. Medi- 
cal history of all study subjects were thoroughly reviewed directly from participants themselves or from their parents and those with conditions that may in any way, alter the findings of the current study were excluded.

\subsection{Study Population}

A sample of 67 patients who were investigating as sickle cell anemia disease, undergo for abdomen CT examination complain of abdominal pain and/or unexplained fever. Patient's data were registered (age, gender, area, presence of family history, type of sickle cell anemia. 28 patients were females, while the 39 were males and their ages are ranged from 10 months to 28 years old. The patients who were affected with sickle cell anemia were from different Saudi Arabian areas; from Eastern Saudi Arabia 1 patient (1.5\%) was affected, from Asseer 11 patients were affected and constituting (16.4\%) and from Gaizan 55 patients were affected and representing (82.1\%) of the total sample 67 (100\%).

\subsection{Machine Used}

General Electric (GE) Hi-speed 60 multidetector CT scanner was used, made by GE Healthcare Manufacturer (2009). With the following specifications, Tube 2.0 MHU MX 135, 3.9 million mAs, Software level 6.03, Fast scan 1.0 sec, Helical plus, 3D max, Power 200 mA, Max 1 mm thickness, Acquisition, Helical 60 Max, Smart pre, DICOM MOD. It has voltage from 70 - $150 \mathrm{Kvp}$ and four options of mA, High (110), medium (77), low (55), and extra low (22). And has three options of slice thickness: $1 \mathrm{~mm}, 3 \mathrm{~mm}$ and $5 \mathrm{~mm}$. Similar scan interspaces, has scan time of $4.8 \mathrm{sec}$, and construction algorithm of normal option (soft tissue), high frequency (bony) and HRCT (for lungs) Images given in CD drive and store in special packs system of the hospital.

\subsection{Technique Used}

Two types of scanning techniques were used, for adults and other for pediatrics. CT scans typically obtained for visualizing all abdominal organs and included axial, coronal and/or sagittal cuts.

\subsubsection{Technique Used in Pediatric: From 0 - 12 Years}

Sedation was used for patient between ages of 6 months and 5 years. They are given IV pentobarbital sodium, 5 $\mathrm{mg} / \mathrm{kg}$ to a maximum dose of $200 \mathrm{mg}$. For patient under 5 years old; a comfortable device for immobilization was used that secures patient's arms beside the head with adhesive straps. For larger children, we used adhesive straps putted under the mattress and over the patient. Scanning protocols were obtain with patient supine, feet first, patient centered with gantry and scan taken from lower chest to symphsis pubic. Thinner slices of $5 \mathrm{~mm}$ used for children 2 years and under $10 \mathrm{~mm}$ slice for children 3 years and older. A $120 \mathrm{kvp}$ with $\mathrm{mA}$ ranged from 150 - $230 \mathrm{~mA}$ was used. Higher pitch of 1 to 2 was used to reduce patient dose, and window of soft tissue was chosen. A plain axial sections (sections before contrast) was taken firstly. The non sedated patients were given dilute Hypaque Sodium which has concentration of $40 \%$ to drink immediately before examination. The amount of oral contrast needed per patients was determining by ages as follow: from 6 months to 1 year given $175 \mathrm{ml}$, from 1 - 5 years $250 \mathrm{ml}$ and from 6 - 12 years given $500-700 \mathrm{ml}$ were given. IV contrast agent was also given: $1-2 \mathrm{ml} / \mathrm{sec}$ Omnipaque through automatic injector just before examination and three stages of scanning were taken. Early arterial phase, venous phase and delayed venous phase.

\subsubsection{Techniques Which Used in Adults: Over 12 Years}

Scans was obtained with patient supine, feet first, patient centered and instructed to be hold his/her breath at end of inspiration. Scan ranged from lower of the chest to iliac crest, and thinner slices of 1.2 to $4 \mathrm{~mm}$ collimation with 1.2 to $4 \mathrm{~mm}$ intervals are used. Rotation time was $0.5 \mathrm{sec}$ with pitch of 1.37 and $\mathrm{kv}$ of 120 with auto mA range $100-400$ and the table feed interval was $27.5 \mathrm{~mm}$. Window setting which used to display images was for evaluation of soft tissue, window width (ww) of 350 - 400 Hounsfield unit (HU) and window level (Wl) of 35 $50 \mathrm{HU}$. Images are reconstructed in coronal and/or sagittal planes. Used very thin slice $(1 \mathrm{~mm})$ to be reconstructed to serve as source images for coronal and/or sagittal reformatted images. A plain axial sections (sections before contrast) was taken firstly. Dilute Barium Sulfate solution (350 - 500) ml of contrast media was given to drink immediately before examination. Intravenous contrast agent was obtained, (2 to $6 \mathrm{ml}$ ) of Omnipaque per second with concentration of $60 \%$ was given to the patient just before examination by automatic injector, and 
three stages of scanning were obtained. The early one was arterial phase scan with typical scan delays of 20 - 30 sec. The later venous phase scans with delays of $60-80$ sec and the last one is delayed scans 1 to 4 hours.

\subsection{Images Evaluation}

All images were evaluated by two radiologist and three technologist, and all patients were evaluated to identify any changes occurred within abdominal organ and lower chest as a complication of sickle cell anemia. The study characterize the changes of spleen size and its correlation with the associated findings including the lesion type, spleen lymph nodes size, spleen CT number spleen, splenic vein diameter. All spleen lesions were characterized in all enhancement phases in order to put good criteria in diagnosis of spleen lesions in patients affected with Sickle cell Anemia. The readings were considered normal as follows length of spleen: In infants, children and adults: (from 1 month to 20 years) in ages ranged between $1-3$ months (Spleen length $=4.6 \mathrm{~cm}$ ), Ages between $10-12$ years (Spleen length $=9.7 \mathrm{~cm}$ ) Ages between $12-15$ years (Spleen length $=10.1 \mathrm{~cm}$ ) Ages between 15 - 20 years (Spleen length $=11.2 \mathrm{~cm}$ ) as mentioned by Henrietta et al. (1991) [20]. Up to $13 \mathrm{~cm}$ length and $7 \mathrm{~cm}$ width in adults consider splenomegaly according to previous studies [21] [22]. Splenic length and width were measured at the level of lower third of T9 which is the highest point of the spleen, We measured both length and width of the spleen according to previous study [23]. The spleen length was measured from the tip of the spleen along the long axis, at the points where spleen gets retrocostal: from dome to tip through the hilum (craniocaudal direction). Measurement of the width of the spleen was made at the hilum. Shape and location: were also been evaluated normal shape commonly has medial concavity and normal location in: LT hypochondria, between funds of stomach and diaphragm.-Normal CT number of spleen: from (40 - $60 \mathrm{HU})$ after Thomas Van Cauwenberghe, et al. (2015) [17]. Splenic vein was measured at the level of L1, posterior to neck of pancreas, normal diameter of splenic vein in CT $0<\mathrm{mm}$, after Unsal NH et al., 2006 [24].

\subsection{Data Analyses}

Data were analyzed using Statistical Package of Social Sciences (SPSS) (Inc., Chicago, Illinois version 16). The data obtained were analyzed statistically and data were presented as frequency and percentages. Paired t-test was used for testing the differences between the variables. The difference at value of $\mathrm{P}<0.05$ will be considered significant.

\section{Results}

Sickle cell types were classified and the description of spleen size, shape and location was obtained for all of the patients. The relation between lesions affected the children spleens and their ages has found to be significantly correlated at $\mathrm{P} \leq 0.033$. In patients aged between 3 month - 10.5 years; 4 were affected with infarction, 7 with cyst 2 with abscess and ages 11 years - 20 years: 4 have infarction, 5 cyst and 3 have abscess, ages ranged between 21 years - 30 years; only 4 were affected with abscess with no children were affected with neither Infarction nor cysts. The present study showed an evidence that the advanced age has significant relation with changing of the spleen size at $\mathrm{P} \leq 0.000$. In patients age ranged: 3 month - $10.5 \mathrm{y}, 28$ have splenomegaly, at ages between 11 y - 20 y 2 were affected and ages ranged between 21 y - 30 years old one patient have splenomegally. The study showed that the relation between lesions that affected the spleen (Infarction, Cyst, and abscess) have significantly related with and enlargement of splenic lymph nodes: $\mathrm{P} \leq 0.012$. Children with enlarged lymph nodes 5 were affected with infarction, 2 with cyst and 7 with abscess.

\section{Discussion}

Sickle cell anemia is one of the most common hereditary blood disorders in Saudi Arabia and it occurs in two different forms, one form in South West of the country is similar to the African type and the other type in the Eastern province is considered to be less severe [25]. In the Eastern province of Saudi Arabia SCA is common with sickle cell trait [26]. The current study showed that the patients who were affected with sickle cell anemia were from different Saudi Arabia areas; Eastern Saudi Arabia is the least number of affected patients (1.5\%) followed by Asseer; affected patients constituting (16.4\%) and from Gaizan representing (82.1\%) of the total sample 67 (100\%). In our study the most common type of SCA affected the Saudi Children is Hemoglobin SS Disease (Hb SS) representing 41 (61.2\%). This was presented in (Figure 1). 


\subsection{Characterization of Spleen in Patients with SCA}

Our study characterize the spleen locations in children affected with SCA; 26 (38.8\%) have splenomegally where 18 (26.9\%) have atrophied spleen this was presented in (Table 1). Characterization of spleen size and shape were done in all of the affected sample with SCA the shape can be changed to be an oval, irregular, blurred out line, pyramidal, loss it's medial concavity. The changes in size may become atrophied or very small like tissue or shrunken, totally calcified or autosplenectomy; the changes occur were found to be of wide-range of variation, this was presented in (Table 2). Studies mentioned that in SCD, the spleen size changes were due

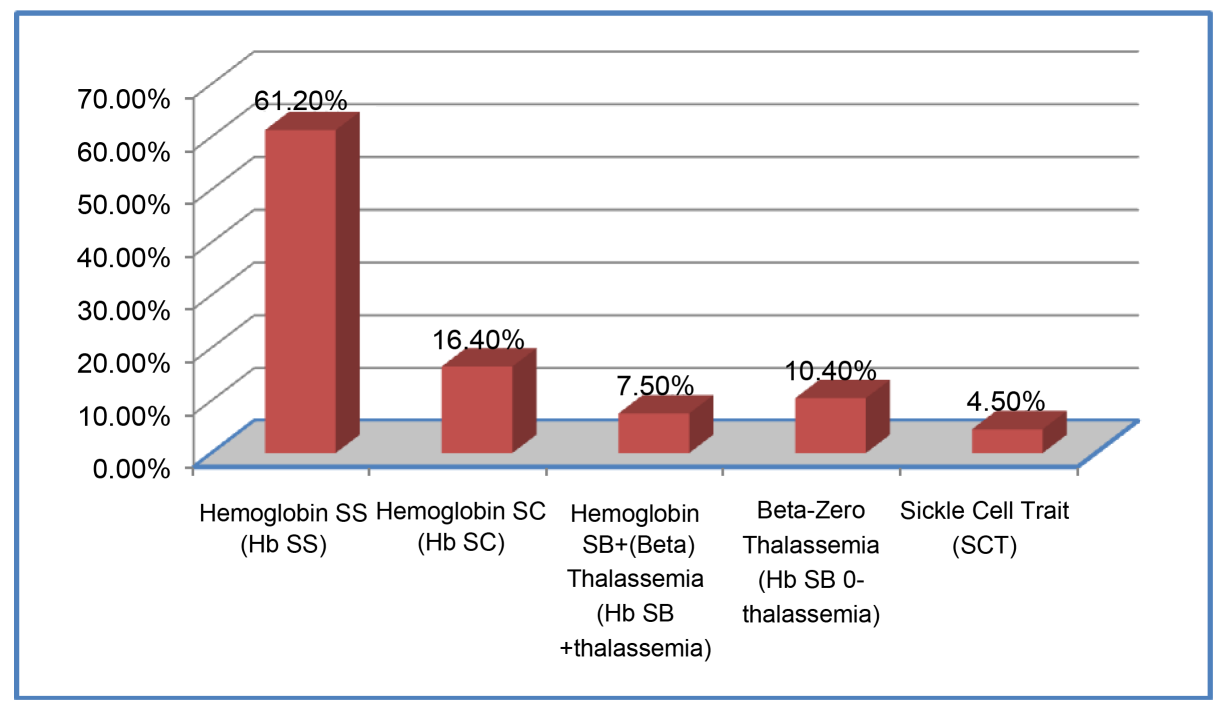

Figure 1. Distribution of Sickle Cell Anemia (SCA) types in the study sample in percentages (\%).

Table 1. Characterize the spleen locations in children affected with Sickle Cell Anemia (SCA), frequency and percentages.

\begin{tabular}{ccc}
\hline Spleen Location & Frequency & Percentages (\%) \\
\hline Normal (Left Hypochondria, between Funds and Diaphragm) & 21 & 31.3 \\
Extend to Left Kidney & 16 & 23.9 \\
Extend Below Lower Third of the Left Kidney & 10 & 14.9 \\
Atrophy & 18 & 26.9 \\
Spleen Is Not Seen & 2 & 3.0 \\
Total & 67 & 100.0 \\
\hline
\end{tabular}

Table 2. Characterization of spleen size and shape in children affected with Sickle Cell Anemia (SCA), frequency and percentages.

\begin{tabular}{|c|c|c|}
\hline Spleen Size/Shape & Frequency & Percentages $(\%)$ \\
\hline Normal size and shape & 21 & 31.3 \\
\hline Enlarged/normal shape & 5 & 7.4 \\
\hline Enlarged, oval shape & 7 & 10.4 \\
\hline Enlarged, irregular line & 4 & 6.0 \\
\hline Enlarged, pyramidal shape & 6 & 9.0 \\
\hline Enlarged \& loss it's medial concavity & 4 & 6.0 \\
\hline Atrophied & 18 & 26.9 \\
\hline Very small tissue like \& totally calcified or autosplenectomy & 2 & 3.0 \\
\hline Total & 67 & 100.0 \\
\hline
\end{tabular}


to repeated attacks of vaso-occlusion and infarction, however sometimes splenomegaly may occur [17], this justify our findings of the presence of various spleen features.

The spleen hilur region was evaluated and the splenic vein was measured 12 (17.9\%) have dilated splenic vein, the presence of multiple vein collaterals, thrombus (filling defect) were also been detected in children with SCD. This was presented in Figure 2.

We characterize such cases in the contrast enhanced CT that show a total absence of or heterogeneous enhancement pattern within the spleen related to partial or total infarction. Findings of infarction on unenhanced CT are low attenuation of the spleen relative to the liver, a hyperdense intraluminal filling defect in the splenic vessels indicating an acute thrombus, and high density of the splenic capsule compared with the parenchyma. Immune-deficiency states due to disease or during immune suppression have emerged as a new, common predisposing cause of splenic abscess [27]. Persistence of splenomegaly in SCA patients predisposes them to the development of complications [28].

The classification of spleen size according to the lesion type in patients affected with sickle cell anemia was done. The infarction affected 9 children where cysts were found in 8 , and abscess in 12 children with significant relations between the type of the complications and the changes in the spleen measurements at $P \leq 0.010$. In the current study; splenomegaly was observed in 10 patients (70\%) with splenic abscess, other findings were observed significantly associated with enlarged spleen in patients with SCD including infarctions and cysts (Table 3).

Table 4 demonstrates the classification of spleen size and the normality of spleen CT number in patients affected with SCA it was found that 12 patients with splenomegally have abnormal attenuation values less than 36 $\mathrm{HU}$ and those with shrunken spleen were 19 patients, this may be due to the affection with cysts and abscess, infarction and inflammation that reduced the attenuation of the spleen, the reduction of the HU was significantly correlated with the changes of the spleen size at $\mathrm{P} \leq 0.004$. Enlargement of spleen lymph nodes in patients affected with SCA were seen in 22 of patients with Splenomegaly with significant relation at $\mathrm{P} \leq 0.000$ between the spleen size changes and the enlargement of lymph nodes, this was presented in (Table 5). Spleen vein dilatation in

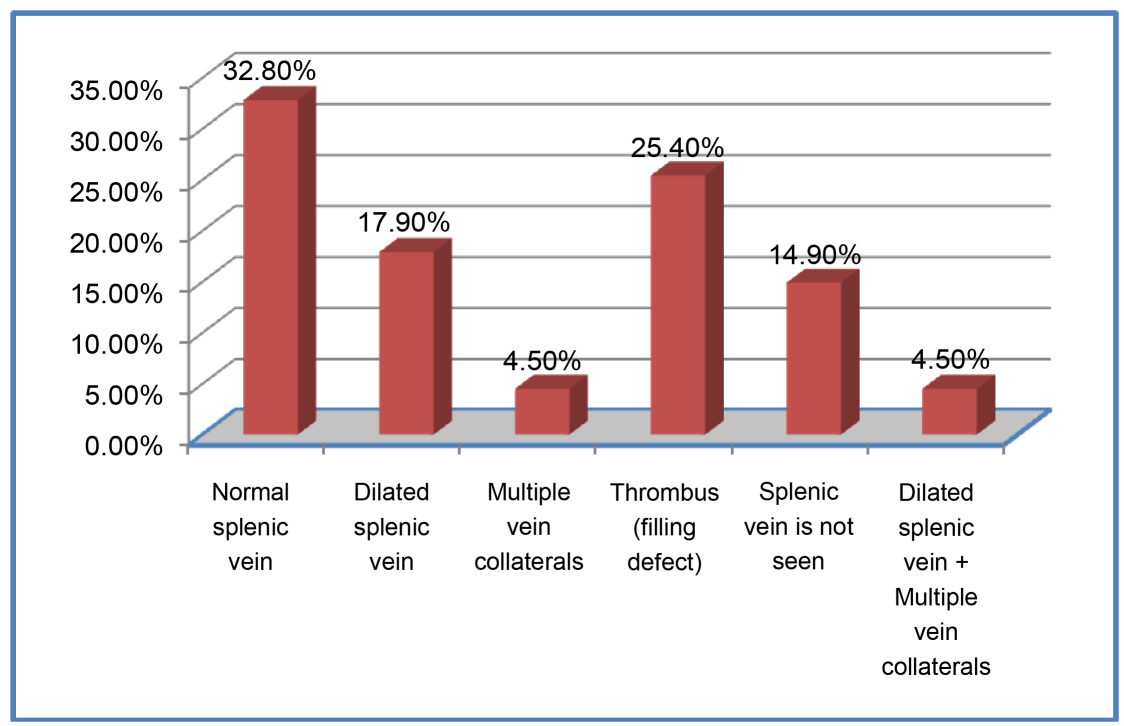

Figure 2. Findings in the spleen hilum region and splenic vein condition in children affected with Sickle Cell Anemia (SCA).

Table 3. Shows the classification of spleen size according to the lesion type in patients affected with Sickle Cell Anemia (SCA).

\begin{tabular}{ccccc}
\hline Size of Spleen & Infarction & Cyst & Abscess & Calcification \\
Splenomegaly & 2 & 1 & - \\
Shrunken Spleen & 5 & 2 & 5 & 5 \\
Normal Spleen Size & 2 & 5 & - \\
\hline
\end{tabular}


patients affected with SCA has significant relations in patients with splenomegaly and those with enlarged lymph nodes, however similar measurements (dilated) were found equally in children affected with cysts, abscess or infarctions, these were noticed in Table 6.

\subsection{Characterization Spleen Lesions in All of the Enhancement Phase in Patients Affected with Sickle Cell Anemia (SCA)}

CT scan pre and post contrast enhancement showed well characteristics of these lesions and differentiated the

Table 4. Shows the classification of spleen size and the normality of spleen CT number in patients affected with Sickle Cell Anemia (SCA).

\begin{tabular}{cccc}
\hline Size of Spleen & Less than $\mathbf{3 6}$ HU (Abnormal) & $\mathbf{4 0}-\mathbf{6 0}$ HU (Normal) & Spleen Doesn't Seen \\
\hline Splenomegaly & 12 & 3 & - \\
Shrunken Spleen & 19 & 11 \\
Normal Spleen Size & 1 & $\mathrm{P} \leq 0.004$ & - \\
\hline
\end{tabular}

Table 5. Shows the classification of spleen size and enlargement of spleen lymph nodes in patients affected with Sickle Cell Anemia (SCA).

\begin{tabular}{cccc}
\hline Size of Spleen & Enlarge Lymph Nodes & Normal & Not Seen \\
\hline Splenomegaly & 22 & 9 & - \\
Shrunken Spleen & 1 & 1 & 22 \\
Normal Spleen Size & 6 & 6 & - \\
\hline
\end{tabular}

Table 6. Shows the cross tabulation between spleen and lymph nodes characteristics and spleen vein diameter in patients affected with Sickle Cell Anemia (SCA).

\begin{tabular}{|c|c|c|c|}
\hline & Dilated Spleen Vein Diameter & Normal Spleen Vein Diameter & Not Seen \\
\hline \multicolumn{4}{|c|}{ Size of Spleen } \\
\hline Splenomegaly & 23 & 8 & - \\
\hline Shrunken Spleen & 9 & - & 15 \\
\hline Normal Spleen Size & 2 & 10 & - \\
\hline \multicolumn{4}{|c|}{$\mathrm{P} \leq 0.000$} \\
\hline \multicolumn{4}{|c|}{ Lymph Nodes Condition } \\
\hline Normal Lymph Nodes & 9 & 9 & 0 \\
\hline Enlarged Lymph Nodes & 20 & 12 & 2 \\
\hline Lymph Nodes Not Seen & 0 & 0 & 15 \\
\hline \multicolumn{4}{|c|}{$\mathrm{P} \leq 0.000$} \\
\hline \multicolumn{4}{|c|}{ Lesions Affected the Spleen } \\
\hline Infarction & 5 & 1 & 3 \\
\hline Cyst & 5 & 6 & 0 \\
\hline Abscess & 5 & 7 & 0 \\
\hline \multicolumn{4}{|c|}{$\mathrm{P} \leq 0.024$} \\
\hline
\end{tabular}


infarction from the cysts and abscesses. Previous studies mentioned that these patients should be evaluated substantially by ultrasound and if in doubt by CT scan of the abdomen. Although ultrasound and CT scan are the best methods for the diagnosis of splenic abscess [29] [30]. We used CT scan because it allows more accurate anatomical localization of the abscess because of the presence of the contrast enhancement techniques. Similarly Nelken et al. reported a 96\% accuracy using CT-scan for the diagnosis of splenic abscess [30].

In our study we characterize the spleen hypo attenuation lesions (abscess, cyst and infarction) in all of the CT procedures pre contrast, arterial phase, venus phase and delay phase. The diagnostic difficulty in patients with SCD is the differentiation between splenic abscess and large splenic infarct, which can also present with a large spleen. The importance of characterization of the lesion type is to reach to early diagnosis of the spleen complications because if not recognized splenic abscess may rupture locally into the peritoneal cavity, into the adjacent bowel, or into the pleural space, leading to increased mortality, these points also were recommended in other previous studies [31].

The CT appearance of the spleen depends on the timing of intravenous bolus administration of contrast material [31]. It may be heterogeneous with variable in appearance patterns include arciform, focal, and diffuse heterogeneity [32]. Table 7 showed that the well enhanced lesions appears well in both venous and delay phase and the difference in enhancement characteristics were significantly related with the scanning phase $\mathrm{P} \leq 0.000$. Studies mentioned that in most of pediatric CT examinations, splenic heterogeneity is resolved within 70 seconds of the beginning of contrast material injection; hence, low-attenuation lesions that are seen after this time should raise suspicion for a disease process. Helical CT scans obtained during the portal venous phase usually demonstrate homogeneous attenuation throughout the spleen [32]. Spleen Abscess in all of the enhancement phase in patients affected with Sickle cell Anemia: is well enhanced in both venus and delay phase, where most of the abscess were ill enhanced in the arterial phase, the current study showed the significant correlations at $\mathrm{P} \leq 0.000$ between degree of abscess enhancement and timing of contrast administration. Cysts are well enhanced in the arterial phase, Spleen Infarction showed well enhancement in the delay phase and were correlated significantly $\mathrm{P} \leq 0.000$ and 0.000 respectively. This was presented in (Tables 8-10).

The absence of wall-thickening, intralesional solid components or contrast-enhancement is in favor of benign lesions [17]. At CT, cysts manifest as rounded, well-demarcated no enhancing lesions with near water attenuation similar description was mentioned previously [33]. These characterizations of cyst in contrast enhancement protocol help us in distinguishing a benign cystic lesion from a malignant lesion. The presence of the infarction in our patients with sickle cell disease was justified that erythrocytes are rigid and frequently occlude the small

Table 7. Characterization spleen lesions in all of the enhancement phase in patients affected with Sickle Cell Anemia (SCA).

\begin{tabular}{ccccc}
\hline Degree of Lesions Enhancement & Before CM & Arterial Phase & Venous Phase & Delay \\
\hline Well Enhanced & 0 & 8 & 15 & 19 \\
Mild Enhanced & 0 & 1 & 15 & 6 \\
Ill Enhanced & 11 & 5 & 0 & 7 \\
Not Appear & 18 & & \\
\hline
\end{tabular}

*Note: The 3 cases (3/32) were of calcification in an atrophied spleen.

Table 8. Characterization spleen abscess in all of the enhancement phase in patients affected with Sickle Cell Anemia (SCA).

\begin{tabular}{ccccc}
\hline Degree of Abscess Enhancement & Before CM & Arterial Phase & Venous Phase & Delay \\
\hline Well Enhanced & 0 & 1 & 8 & 9 \\
Mild Enhanced & 0 & 0 & 0 & 1 \\
Ill Enhanced & 2 & 2 & 0 & 0 \\
Not Appear & 10 & & \\
\hline
\end{tabular}


sinuses of the red pulp. This leads to micro infarctions and micro-hemorrhage [34]. When we apply the contrast material, it becomes visible as small, disseminated hypodense, ill-defined lesions. It was present in early and late course of the disease, within enlarged spleen however in some cases the spleen shrinks and become calcified (Tables 11-14). Therefore, in patients with sickle cell disease, the presence of multiple small hypodense splenic lesions, is strongly suggestive of sickle cell-induced splenic infarctions. When we characterize children with splenic infarction, The CT appearance of infarcts was found to be reliant on the time elapsed since the insult. On non-enhanced CT, infarcts are poorly visualized. In the hyper acute phase, the spleen demonstrates a mottled texture secondary to hemorrhagic infarction with intravenous administration of contrast material. When the entire spleen is infarcted, it results in diffuse splenic hypodensity, leaving a residual rim of enhancing capsule. This appearance was described in the study done by Taylor et al. (1991) as known as the rim sign [34]. Over time, the lesions become better defined. Infarctions are peripheral and wedge-shaped non-enhancing defects; however some cases have an irregular margin, at delay phase the lesions were resolved (wash out), leaving the cortical defect, calcification and the rim of enhancing capsule. The diagnosis and characterization of infarction is very critical because some infarcts may mimic other splenic lesions, including abscesses or tumours, requiring clinical correlation, or percutaneous fine-needle aspiration biopsy [34].

Table 9. Characterization spleen cyst in all of the enhancement phase in patients affected with Sickle Cell Anemia (SCA).

\begin{tabular}{ccccc}
\hline Degree of Cyst Enhancement & Before CM & Arterial Phase & Venous Phase & Delay \\
\hline Well Enhanced & 0 & 7 & 3 & 0 \\
Mild Enhanced & 0 & 1 & 5 & 0 \\
Ill Enhanced & 7 & 0 & 0 & 7 \\
Not Appear & 1 & & \\
& & &
\end{tabular}

Table 10. Characterization spleen infarction in all of the enhancement phase in patients affected with Sickle Cell Anemia (SCA).

\begin{tabular}{ccccc}
\hline Degree of Infarction Enhancement & Before CM & Arterial Phase & Venous Phase & Delay \\
\hline Well Enhanced & 0 & 0 & 4 & 9 \\
Mild Enhanced & 0 & 0 & 4 & 0 \\
Ill Enhanced & 2 & 3 & 0 & 0 \\
Not Appear & 7 & & \\
\end{tabular}

Table 11. Characterization spleen lesions before CM in patients affected with different type Sickle Cell Anemia types (Hb SB + thalassemia, Hb SB 0-thalassemia, Hb SC, Hb SS and SCT).

\begin{tabular}{|c|c|c|c|c|c|c|c|}
\hline & & \multicolumn{5}{|c|}{ Type of Sickle } & \multirow{2}{*}{ Total } \\
\hline & & $\begin{array}{l}\mathrm{Hb} \text { SB + } \\
\text { thalassemia }\end{array}$ & Hb SB 0-thalassemia & $\mathrm{Hb}$ SC & $\mathrm{Hb}$ SS & SCT & \\
\hline \multirow{6}{*}{ 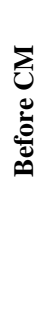 } & Not appear & - & $3(9.4 \%)$ & $5(15.6 \%)$ & $13(40.6 \%)$ & - & $21(65.6 \%)$ \\
\hline & Ill defined lesions & - & $1(3.1 \%)$ & - & $4(12.5 \%)$ & $1(3.1 \%)$ & $6(18.8 \%)$ \\
\hline & Well defined calcifications & $1(3.1 \%)$ & $1(3.1 \%)$ & - & $1(3.1 \%)$ & - & $3(9.4 \%)$ \\
\hline & Well defined nodules & $1(3.1 \%)$ & - & $1(3.1 \%)$ & - & - & $2(6.3 \%)$ \\
\hline & \multirow[t]{2}{*}{ Total } & $2(6.3 \%)$ & $5(15.6 \%)$ & $6(18.8 \%)$ & $18(56.3 \%)$ & $1(3.1 \%)$ & $32(100.0 \%)$ \\
\hline & & & $P$-value $=0.047$ & & & & \\
\hline
\end{tabular}


Table 12. Characterization spleen lesions in arterial phase in patients affected with different type Sickle Cell Anemia (Hb SB + thalassemia, Hb SB 0-thalassemia, Hb SC, Hb SS, SCT).

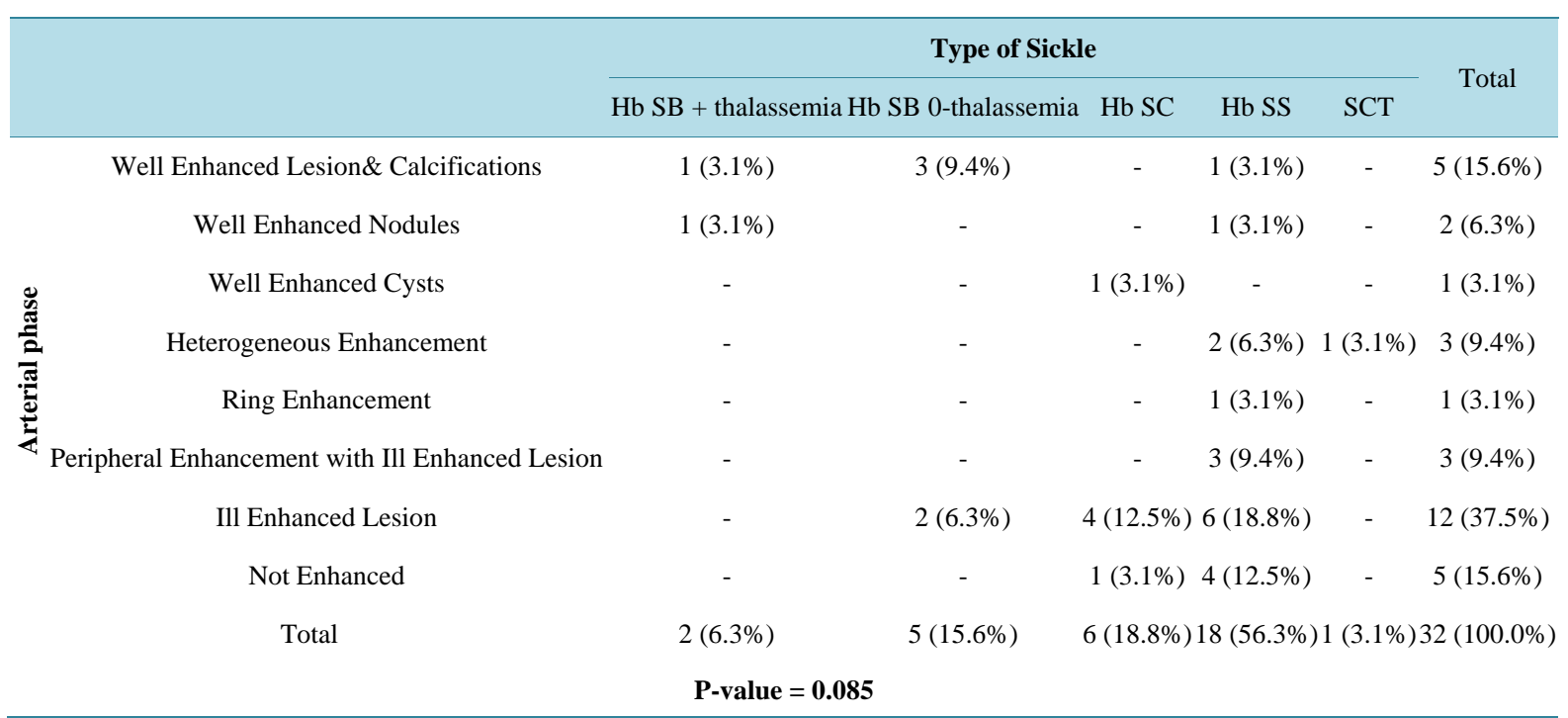

Table 13. Characterization spleen lesions venous phase in patients affected with different type Sickle cell Anemia Hb SB + thalassemia, Hb SB 0-thalassemia, Hb SC, Hb SS, SCT.

\begin{tabular}{|c|c|c|c|c|c|c|c|}
\hline & & \multicolumn{5}{|c|}{ Type of Sickle } & \multirow{2}{*}{ Total } \\
\hline & & $\begin{array}{l}\mathrm{Hb} \mathrm{SB}+ \\
\text { thalassemia }\end{array}$ & Hb SB 0-thalassemia & Hb SC & Hb SS & SCT & \\
\hline \multirow{10}{*}{ 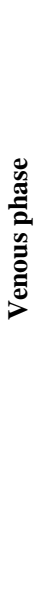 } & Well defined enhanced lesion & - & - & $1(3.1 \%)$ & $2(6.3 \%)$ & $1(3.1 \%)$ & $4(12.5 \%)$ \\
\hline & Well defined non enhanced lesion (hypo dense) & - & $2(6.3 \%)$ & $3(9.4 \%)$ & $10(31.3 \%)$ & $0(0.0 \%)$ & $15(46.9 \%)$ \\
\hline & Multiple well defined non enhance lesions & - & - & - & $2(6.3 \%)$ & - & $2(6.3 \%)$ \\
\hline & Peripheral hypo dense enhanced lesion & - & - & - & $1(3.1 \%)$ & - & $1(3.1 \%)$ \\
\hline & Hypo dense lesion surround by enhancing calcification & - & $1(3.1 \%)$ & - & - & - & $1(3.1 \%)$ \\
\hline & $\begin{array}{c}\text { Homogenous hypo dense with well defined peripheral } \\
\text { enhancement }\end{array}$ & - & - & - & $2(6.3 \%)$ & - & $2(6.3 \%)$ \\
\hline & Heterogeneous pattern & - & - & $1(3.1 \%)$ & - & - & $1(3.1 \%)$ \\
\hline & Ill defined non enhanced lesion (hypo dense) & $2(6.3 \%)$ & $2(6.3 \%)$ & $1(3.1 \%)$ & $1(3.1 \%)$ & - & $6(18.8 \%)$ \\
\hline & \multirow[t]{2}{*}{ Total } & $2(6.3 \%)$ & $5(15.6 \%)$ & \multirow{2}{*}{\multicolumn{4}{|c|}{$6(18.8 \%) 18$ (56.3\%) 1 (3.1\%) 32 (100.0\%) }} \\
\hline & & P-value $=$ & 0.037 & & & & \\
\hline
\end{tabular}

The current study characterized 3 cases of atrophied spleen with calcifications; in the noncontract films CT represented this dense splenic calcification. The current study justify this finding as it thought to be secondary to a combination of hemosiderin deposition, fibrosis as mentioned by Lieven et al. [35]. splenic abscess formation was also been detected At CT, abscesses typically manifest irregularly marginated lesions with low attenuation. Rim enhancement was seen on contrast-enhanced scans, this is also described by Urrutia M et al. (1996) [36]. The enhancement pattern in different type of SCD were seen in all of the CT scanning phase, in arterial, venus and delay phase as well as scanning before contrast, the results showed a significant relation between the character of the lesions and degree of enhancement with the scanning technique used (pre contrast, venous and delay phase) in different SCA types that means it may have an impact on the lesions enhancement however the correlation in characterizing or defining lesion is found to be frail at $\mathrm{p} \leq 0.085$ in the arterial phase, that means we have to consider the other phases in confirmation or identifying the hypo intense splenic lesions, these were presented in (Tables 11-14). 
Table 14. Characterization spleen lesions in delay phase in patients affected with different type Sickle Cell Anemia Hb SB + thalassemia, Hb SB 0-thalassemia, Hb SC, Hb SS, SCT.

\begin{tabular}{|c|c|c|c|c|c|c|c|}
\hline & & \multicolumn{5}{|c|}{ Type of Sickle } & \multirow{2}{*}{ Total } \\
\hline & & $\begin{array}{l}\mathrm{Hb} \mathrm{SB}+ \\
\text { thalassemia }\end{array}$ & $\begin{array}{c}\text { Hb SB } \\
\text { 0-thalassemia }\end{array}$ & $\mathrm{Hb} \mathrm{SC}$ & Hb SS & SCT & \\
\hline \multirow{7}{*}{ 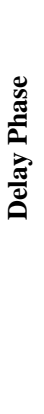 } & Well defined enhanced lesion & - & - & $1(3.1 \%)$ & $1(3.1 \%)$ & $1(3.1 \%)$ & $3(9.4 \%)$ \\
\hline & Well defined hypo dense lesion & - & $3(9.4 \%)$ & $3(9.4 \%)$ & $12(37.5 \%)$ & - & $18(56.3 \%)$ \\
\hline & $\begin{array}{l}\text { Well defined peripheral enhance } \\
\text { with unenhanced hypo dense lesion }\end{array}$ & - & - & - & $2(6.3 \%)$ & - & $2(6.3 \%)$ \\
\hline & Ill defined unenhanced lesion & $1(3.1 \%)$ & - & $2(6.3 \%)$ & $1(3.1 \%)$ & - & $4(12.5 \%)$ \\
\hline & Washout CM (not seen) & $1(3.1 \%)$ & $2(6.3 \%)$ & - & $2(6.3 \%)$ & - & $5(15.6 \%)$ \\
\hline & Total & $2(6.3 \%)$ & $5(15.6 \%)$ & $6(18.8 \%)$ & $18(56.3 \%)$ & $1(3.1 \%)$ & $32(100.0 \%)$ \\
\hline & \multicolumn{7}{|c|}{$P$-value $=0.055$} \\
\hline
\end{tabular}

\section{Conclusions}

In sickle cell anemia hypodense splenic lesions are frequently encountered on abdominal CT images. Although most hypodense lesions of the spleen can be considered benign, some findings necessitate closer attention to the lesion. CT offers a number of morphological criteria that can be applied to characterize the spleen and to differentiate hypodense lesions of the spleen, such as the appearance of a lesion's borders, its attenuation, SCA types as well as the presence of calcifications or solid components.

Children with SCD are frequently exposed to diagnostic radiation so a justifiable indication and proper practice is necessary for all CT selected procedures. The selection of CT sequences and contrast examination phase in diagnosis of SCA should be minimized in order to limit judiciously the exposure of children with SCD to unnecessarily diagnostic radiation. This characterization and the elucidation of imaging findings of hypodense splenic lesions are an attempt to highlight the best phase to interpret the splenic lesion in symptomatic patients with sickle cell disease.

\section{References}

[1] Desai, D.V. and Hiren, D. (2004) Sickle Cell Disease: History and Origin. The Internet Journal of Haematology, 2, 47.

[2] Al-Salem, A.H. (2006) Indications and Complications of Splenectomy for Children with Sickle Cell Disease. Journal of Pediatric Surgery, 41, 1909-1915. http://dx.doi.org/10.1016/j.jpedsurg.2006.06.020

[3] Al-Salem, A.H. (2011) Splenic Complications of Sickle Cell Anemia and the Role of Splenectomy. ISRN Hematology, 864257. http://dx.doi.org/10.5402/2011/864257

[4] Al-Salem, A.H. (2013) Massive Splenic Infarction in Children with Sickle Cell Anemia and the Role of Splenectomy. Pediatric Surgery International, 29, 281-285.

[5] Berger, E., Saunders, N., Wang, L., et al. (2009) Sickle Cell Disease in Children: Differentiating Osteomyelitisfrom Vaso-Occlusive Crisis. Archives of Pediatrics and Adolescent Medicine Journal, 163, 251-255. http://dx.doi.org/10.1001/archpediatrics.2008.545

[6] Almeida, A. and Roberts, I. (2005) Bone Involvement in Sickle Cell Disease. British Journal of Haematology, 129, 482-490. http://dx.doi.org/10.1111/j.1365-2141.2005.05476.x

[7] Rabushka, L.S., Kawasbima, A. and Fishman, E.K. (1994) Imaging of the Spleen: CT with Supplemental MR Examination. RadioGraphics, 14, 307-332. http://dx.doi.org/10.1148/radiographics.14.2.8190956

[8] Catalano, O., Sandomenico, F., Vallone, P., D’Errico, A.G. and Siani, A. (2006) Contrast-Enhanced Sonography of the Spleen. Seminars in Ultrasound, CT and MRI, 27, 426-433. http://dx.doi.org/10.1053/j.sult.2006.06.006

[9] Vanhoenacker, F.M., Op de Beeck, B., De Schepper, A.M., Salgado, R., Snoeckx, A. and Parizel, P.M. (2007) Vascular Disease of the Spleen. Seminars in Ultrasound, CT, and MRI, 28, 35-51. http://dx.doi.org/10.1053/j.sult.2006.10.006

[10] Slovis, T.L. and Berdon, W.E. (2002) Panel Discussion. Pediatric Radiology, 32, 242-244. http://dx.doi.org/10.1007/s00247-002-0674-y 
[11] Donnelly, L.F. (2005) Reducing Radiation Dose Associated with Pediatric CT by Decreasing Unnecessary Examinations. American Journal of Roentgenology, 184, 655-657. http://dx.doi.org/10.2214/ajr.184.2.01840655

[12] Renton, J., Kincaid, S. and Ehrlich, P.F. (2003) Shouldhelical CT Scanning of the Thoracic Cavityreplace the Conventional Chest X-Ray as a Primary Assessment Tool in Pediatric Trauma? An Efficacy and Cost Analysis. Journal of Pediatric Surgery, 38, 793-797. http://dx.doi.org/10.1016/jpsu.2003.50169

[13] Kaups, K.L., Davis, J.W. and Parks, S.N. (2004) Routinely Repeated Computed Tomography after Blunt Head Trauma: Does It Benefit Patients? Journal of Trauma, 56, 475-480. http://dx.doi.org/10.1097/01.TA.0000114304.56006.D4

[14] Maytal, J., Krauss, J.M., Novak, G., Nagelberg, J. and Patel, M. (2000) The Role of Brain Computed Tomography in Evaluating Children with New Onset of Seizures in the Emergency Department. Epilepsia, 41, 950-954. http://dx.doi.org/10.1111/j.1528-1157.2000.tb00277.x

[15] Lewis, D.W. and Dorbad, D. (2000) The Utility of Neuroimaging in the Evaluation of Children with Migraine or Chronic Daily Headache Who Have Normal Neurological Examinations. Headache, 40, 629-632. http://dx.doi.org/10.1046/j.1526-4610.2000.040008629.x

[16] Stephen, A.E., Segev, D.L., Ryan, D.P., et al. (2003) The Diagnosis of Acute Appendicitis in a Pediatric Population: To CT or Not to CT. Journal of Pediatric Surgery, 38, 367-371. http://dx.doi.org/10.1053/jpsu.2003.50110

[17] Vancauwenberghe, T., Snoeckx, A., Vanbeckevoort, D., Dymarkowski, S. and Vanhoenacker, F.M. (2015) Imaging of the Spleen: What the Clinician Needs to Know Singapore. Singapore Medical Journal, 56, 133-144.

[18] Fenchel, S., Boll, D.T., Fleiter, T.R., Brambs, H.J. and Merkle, E.M. (2003) Multislice Helical CT of the Pancreas and Spleen. European Journal of Radiology, 45, S59-S72. http://dx.doi.org/10.1016/S0720-048X(02)00363-7

[19] Brousse, V., Buffet, P. and Rees, D. (2014) The Spleen and Sickle Cell Disease: The Sick(Led) Spleen. British Journal of Haematology, 166, 165-176.

[20] Rosenberg, H.K., Markowitz, R.I., Kolberg, H., Park, C., Hubbard, A. and Bellah, R.D. (1991) Normal Splenic Size in Infants and Children: Sonographic Measurements. American Journal of Roentgenology, 157, 119-121.

[21] Prassopoulos, P., Daskalogiannaki, M., Raissaki, M., Hatjidakis, A. and Gourtsoyiannis, N. (1997) Determination of Normal Splenic Measurements on Computed Tomography in Relation to Age, Gender and Body Habitus. European Radiology, 7, 246-248. http://dx.doi.org/10.1007/s003300050145

[22] Bezerra, A.S., D’Ippolito, G., Faintuch, S., Szejnfeld, J. and Ahmeds, M. (2005) Determination of Splenomegaly by CT: Is There a Place for a Single Measurement? American Journal of Roentgenology, 184, 1510-1513. http://dx.doi.org/10.2214/ajr.184.5.01841510

[23] Yildiz, A.E., Ariyurek, M.O. and Karcaaltincaba, M. (2013) Splenic Anomalies of Shape, Size, and Location: Pictorial Essay. The Scientific World Journal, 2013, Article ID: 321810. http://dx.doi.org/10.1155/2013/321810

[24] Ünsal, N.H., Erden, A. and Erden, İ. (2006) Evaluation of the Splenic Vein Diameter and Longitudinal Size of the Spleen in Patients with Gamna-Gandy Bodies. Diagnostic and Interventional Radiology, 12, 125-128.

[25] Padmos, M.A., Robert, G.T., Sacky, K., Kulozik, A., Bail, S., Morris, J.S., Serjeant, B.E. and Serjeant, G.R. (1991) Two Different Forms of Homozygous Sickle Cell Disease Occur in Saudi Arabia. British Journal of Haematology, 79, 93-98. http://dx.doi.org/10.1111/j.1365-2141.1991.tb08013.x

[26] AL-Jama, A.H., AL-Dabbous, I.A., Chirala, S.K., AL-Majid, H. and AL-Ali, J. (2000) Splenic Function in Sickle Cell Anemia Patients in Qatif, Saudi Arabia. American Journal of Hematology, 63, 68-73. http://dx.doi.org/10.1002/(SICI)1096-8652(200002)63:2<68::AID-AJH2>3.0.CO;2-N

[27] Smith Jr., M.D., Nio, M., Camel, J.E., Sato, J.K. and Atkinson, J.B. (1993) Management of Splenic Abscess in Immunocompromised Children. Journal of Pediatric Surgery, 28, 823-826. http://dx.doi.org/10.1016/0022-3468(93)90336-J

[28] Wilson-Okoh, D.A., Nwauche, C.A. and Ejele, O.A. (2006) Splenic Changes in Sickle Cell Anaemia. Nigerian Journal of Medicine, 15, 20-23.

[29] Ralls, P.W., Quinn, M.F., Colletti, P., Lapin, S.A. and Halls, J. (1982) Sonography of Pyogenic Splenic Abscess. American Journal of Roentgenology, 138, 523-525. http://dx.doi.org/10.2214/ajr.138.3.523

[30] Nelken, N., Ignatius, J., Skinner, M. and Christensen, N. (1987) Changing Clinical Spectrum of Splenic Abscess: A Multicenter Study and Review of Literature. The American Journal of Surgery, 154, 27-34. http://dx.doi.org/10.1016/0002-9610(87)90285-6

[31] Urban, B.A. and Fishman, E.K. (1998) Helical CT of Spleen. American Journal of Roentgenology, 170, 997-1003.

[32] Donnelly, L.F., Foss, J.N., Frush, D.P. and Bisset, G.S.III. (1999) Heterogeneous Splenic Enhancement Patterns on Spiral CT Images in Children: Minimizing Misinterpretation. Radiology, 210, 493-497. http://dx.doi.org/10.1148/radiology.210.2.r99fe16493

[33] Karlo, C.A., Stolzmann, P., Do, R.K. and Alkadhi, H. (2013) Computed Tomography of the Spleen: How to Interpret the Hypodense Lesion. Insights into Imaging, 4, 65-76. http://dx.doi.org/10.1007/s13244-012-0202-z 
[34] Taylor, A.J., Dodds, W.J., Erickson, S.J. and Stewart, E.T. (1991) CT of Acquired Abnormalities of the Spleen. American Journal of Roentgenology, 157, 1213-1219. http://dx.doi.org/10.2214/ajr.157.6.1950868

[35] Levin, T.L., Berdon, W.E., Haller, J.O., Ruzal-Shapiro, C. and Hurlet-Jenson, A. (1996) Intrasplenic Masses of "Preserved” Functioning Splenic Tissue in Sickle Cell Disease: Correlation of Imaging Findings (CT, Ultrasound, MRI, and Nuclear Scintigraphy). Pediatric Radiology, 26, 646-649. http://dx.doi.org/10.1007/BF01356826

[36] Urrutia, M., Mergo, P.J., Ros, L.H., Torres, G.M. and Ros, P.R. (1996) Cystic Masses of the Spleen: Radiologic-Pathologic Correlation. RadioGraphics, 16, 107-129. http://dx.doi.org/10.1148/radiographics.16.1.107

\section{Submit or recommend next manuscript to SCIRP and we will provide best service for you:}

Accepting pre-submission inquiries through Email, Facebook, LinkedIn, Twitter, etc.

A wide selection of journals (inclusive of 9 subjects, more than 200 journals)

Providing 24-hour high-quality service

User-friendly online submission system

Fair and swift peer-review system

Efficient typesetting and proofreading procedure

Display of the result of downloads and visits, as well as the number of cited articles

Maximum dissemination of your research work

Submit your manuscript at: http://papersubmission.scirp.org/ 